\title{
ADNP Regulates Cognition: A Multitasking Protein
}

\author{
Illana Gozes * \\ Laboratory for Molecular Neuroendocrinology, Department of Human Molecular Genetics and Biochemistry, Sackler Faculty \\ of Medicine, Sagol School of Neuroscience and Adams Super Center for Brain Studies, Tel Aviv University, Tel Aviv, Israel
}

Keywords: ADNP (activity dependent neuroprotective protein), ADNP gene, cognition, protein interaction, neurodegenaration

\section{INTRODUCTION}

With the advantage of rapid progress of DNA/RNA sequencing techniques, it has become feasible to identify the cause of developmental disorders encompassing intellectual disabilities to single de novo mutated genes (e.g., Larsen et al., 2016; Deciphering Developmental Disorders, 2017; Stessman et al., 2017). It is my opinion that we should study in depth, the leading identified genes, to acquire better understanding of the molecular basis for human cognitive functions. Furthermore, from a translational science point of view, understanding genes regulating cognition will facilitate drug development to currently untreatable devastating disease, which hamper cognition. Here, I focus on activity-dependent neuroprotective protein (ADNP) (Gozes et al., 2018) showing a tight association with cognition, and in my opinion, a key gene regulating cognitive functions.

\section{ACTIVITY-DEPENDENT NEUROPROTECTIVE PROTEIN (ADNP)}

\section{OPEN ACCESS}

Edited by:

Mark P. Burns,

Georgetown University, United States

Reviewed by:

Corrado Romano,

Associazione Oasi Maria SS. Onlus

(IRCCS), Italy

*Correspondence:

Illana Gozes

igozes@tauex.tau.ac.il

Specialty section:

This article was submitted to

Neurodegeneration,

a section of the journal

Frontiers in Neuroscience

Received: 04 October 2018 Accepted: 08 November 2018 Published: 26 November 2018

Citation:

Gozes I (2018) ADNP Regulates Cognition: A Multitasking Protein.

Front. Neurosci. 12:873.

doi: 10.3389/fnins.2018.00873
Our original studies identified vasoactive intestinal peptide (VIP) (Bodner et al., 1985) as a gene/protein highly expressed at the time of synapse formation (Gozes et al., 1987), which was translated to VIP-associated neuroprotection (Brenneman and Eiden, 1986) and VIP-related synaptogenesis, through astrocyte activation (Blondel et al., 2000). Astrocyte activation entailed secretion of protein growth factors, leading to the cloning/discovery of ADNP and its active neuroprotective site, NAP (NAPVSIPQ) (Bassan et al., 1999; Zamostiano et al., 2001). To elucidate ADNP's in vivo activity we knocked out the ADNP gene and showed that this gene is essential for neural tube closure and brain formation (Pinhasov et al., 2003). At the single cell level, $\mathrm{ADNP}$ is found in the nucleus and upon neuronal maturation, the protein is found also in the cytoplasm with specific RNA silencing resulting in loss of microtubules/loss of neurites (Mandel et al., 2008). While complete knockout of ADNP is lethal, haploinsufficient (heterozygous) mice survive, showing cognitive impairment (Vulih-Shultzman et al., 2007). Further results indicate microtubule insufficiency, reduced axonal transport (Amram et al., 2016) and reduced dendritic spines (Hacohen-Kleiman et al., 2018) in the $A d n p^{+/-}$mice. These findings are in line with patient results showing intellectual disabilities in case of ADNP gene heterozygous microdeletion or truncating mutation (Borozdin et al., 2007; Vandeweyer et al., 2014; Huynh et al., 2018). Given the fact that ADNP is a large protein it includes many identified signature motifs for macromolecular interactions and here I will concentrate on the ADNP motifs, protein interactors and the strong link to cognition.

\section{ADNP BINDING MOTIFS}

ADNP contains a nuclear localization signal (NLS) and a homeobox domain profile (Bassan et al., 1999; Zamostiano et al., 2001). ADNP has heterochromatin protein 1 (HP1) binding 
domains (Mandel et al., 2007; Mosch et al., 2011) and interacts with DNA in a sequence-specific manner, as well as with HP1 (Mandel et al., 2007; Mosch et al., 2011) and chromodomainhelicase-DNA-binding protein 4 (CHD4) (Ostapcuk et al., 2018). ADNP was discovered to bind and affect the SWItch/Sucrose Non-Fermentable (SWI/SNF) chromatin remodeling complex (Mandel and Gozes, 2007) also associated with alternative RNA splicing (Schirer et al., 2014). The DNA/chromatin binding characteristics have been further implicated in promoter/control gene specific regions for ADNP binding and direct regulation of RNA expression (Mandel et al., 2007; Dresner et al., 2012). Complete gene array analysis, RNA-seq and high-throughput platform BioMark ${ }^{\mathrm{TM}}$ HD System (Fluidigm) identified hundreds of ADNP regulated transcripts (Mandel et al., 2007; Amram et al., 2016; Hacohen-Kleiman et al., 2018) suggesting a master gene regulator function.

In the cytoplasm, ADNP was found to bind eukaryotic initiation factor $4 \mathrm{E}$ (Eif4e), implicating an involvement in the protein translation machinery (Malishkevich et al., 2015) and the autophagy complex, by direct binding to microtubule associated protein 1 light chain 3B (LC3B) (Merenlender-Wagner et al., 2015; Sragovich et al., 2017). ADNP provides potent neurotrophic/neuroprotective activity that can be attributed, at least in part, to NAP (davunetide, AL-108 or CP201 (Bassan et al., 1999; Gozes et al., 2018). In short, the SIP domain in NAP interacts with microtubule end binding proteins (EB1 and EB3) enhancing ADNP (Esteves et al., 2014) and tau (IvashkoPachima et al., 2017) interaction with microtubules. This SxIP (SKIP) domain in NAP further protects against deficits in axonal transport occurring because of ADNP deficiency (Amram et al., 2016) and NAP enhances ADNP interaction with the autophagosome membrane protein LC3B (Merenlender-Wagner et al., 2015). In vivo NAP restores multiple anomalies caused by ADNP haploinsufficiency (Vulih-Shultzman et al., 2007; Hacohen-Kleiman et al., 2018). Lastly, our original studies have shown that ADNP has a glutaredoxin active site (Bassan et al., 1999).

\section{PROTEINS INTERACTING WITH ADNP}

Ten ADNP-interacting proteins were identified when analyzing (string) for human genes and 9 proteins when searching for mouse associations, with 6 overlapping proteins (Figure 1). Some of these proteins are described in the section above. The common mouse and human proteins, not described above, include ZFP161-Zinc finger protein 161 homolog (mouse), which is a transcriptional activator of the dopamine transporter (DAT). ZFP161 also acts as a repressor of the FMR1 gene (fragile $\mathrm{X}$ syndrome). We have originally shown that ZF5 is linked to regulation by ADNP in the developing mouse embryos (Mandel et al., 2007). Another shared mouse and human protein, EBNA1BP2 is linked to early onset Alzheimer's disease (https:// www.malacards.org/card/early_onset_familial_alzheimer_ disease). A third one, SAP18 enhances the ability of SIN3HDAC1-mediated transcriptional repression. When tethered to the promoter, it can direct the formation of a repressive complex to core histone proteins. SAP18 is an auxiliary component of the splicing-dependent multiprotein exon junction complex (EJC) deposited at splice junction on mRNAs, and our laboratory has shown interaction of ADNP with the RNA splicing machinery (Schirer et al., 2014). ADNP-interacting proteins described for either human or mouse, include actin-interacting proteins (EMD - nuclear), SEPT2 - cytoplasmic and Spna2-associated with the cytoskeleton. Other interacting proteins are NFIA, linked to viral infection, PHGDH, linked to cytoplasmic energy metabolism and SAP18b (Gm10094, http://www.informatics.jax.org/marker/ MGI:1277978).

\section{ADNP AND COGNITION}

Our studies showed that VIP and VIP derivatives protected against Alzheimer-like pathology (Gozes et al., 1996, 1999). Furthermore, the VIP receptor, VPAC2, controlling ADNP expression (Zusev and Gozes, 2004), has been linked to schizophrenia and autism spectrum disorders (Vacic et al., 2011; Ago et al., 2018) and VIP regulates ADNP expression in vivo (Giladi et al., 2007). Our discovery of the requirement of ADNP for brain formation (Pinhasov et al., 2003) coupled with the finding that a major phenotypic outcome of ADNP haploinsufficency in mice leads to cognitive impairments, placed $\mathrm{ADNP}$ as a key regulatory gene for brain function (Vulih-Shultzman et al., 2007). The direct involvement of ADNP in cognitive function was reported in our 2007 Adnp haploinsufficient mouse model (Vulih-Shultzman et al., 2007) coupled with a paper showing that deletion in the chromosomal area including ADNP [20q12-13.2 (Zamostiano et al., 2001)] specifically, 20q13.13-q13.2 (Borozdin et al., 2007) resulted in developmental delays and intellectual disabilities in humans. Both animal studies (Malishkevich et al., 2015; Amram et al., 2016; Hacohen-Kleiman et al., 2018) as well as the human studies were repeated and extended showing axonal/synaptic/behavioral dysfunctions at the mouse level (Amram et al., 2016; HacohenKleiman et al., 2018) mirroring the human situation when the ADNP gene is partially deleted (Huynh et al., 2018) or pathologically mutated (Helsmoortel et al., 2014; Vandeweyer et al., 2014; Gozes et al., 2015, 2017a,b, 2018; Arnett et al., 2018; Van Dijck et al., 2018). Over the last 4 years it became apparent that the mutated $A D N P$ gene is consistently reported as one of the most frequent causes of syndromic autism and intellectual disability (Helsmoortel et al., 2014; Larsen et al., 2016; Deciphering Developmental Disorders, 2017; Stessman et al., 2017).

Notably, the involvement of ADNP in cognitive performance is not limited to the ADNP syndrome but is extended to schizophrenia (Merenlender-Wagner et al., 2015) and Alzheimer's disease (Malishkevich et al., 2016) with ADNP transcripts dysregulated in lymphocytes in both diseases and with ADNP blood levels correlating with intelligence (Malishkevich et al., 2016). Thus, the current opinion combines mechanisms to cognitive protection. 


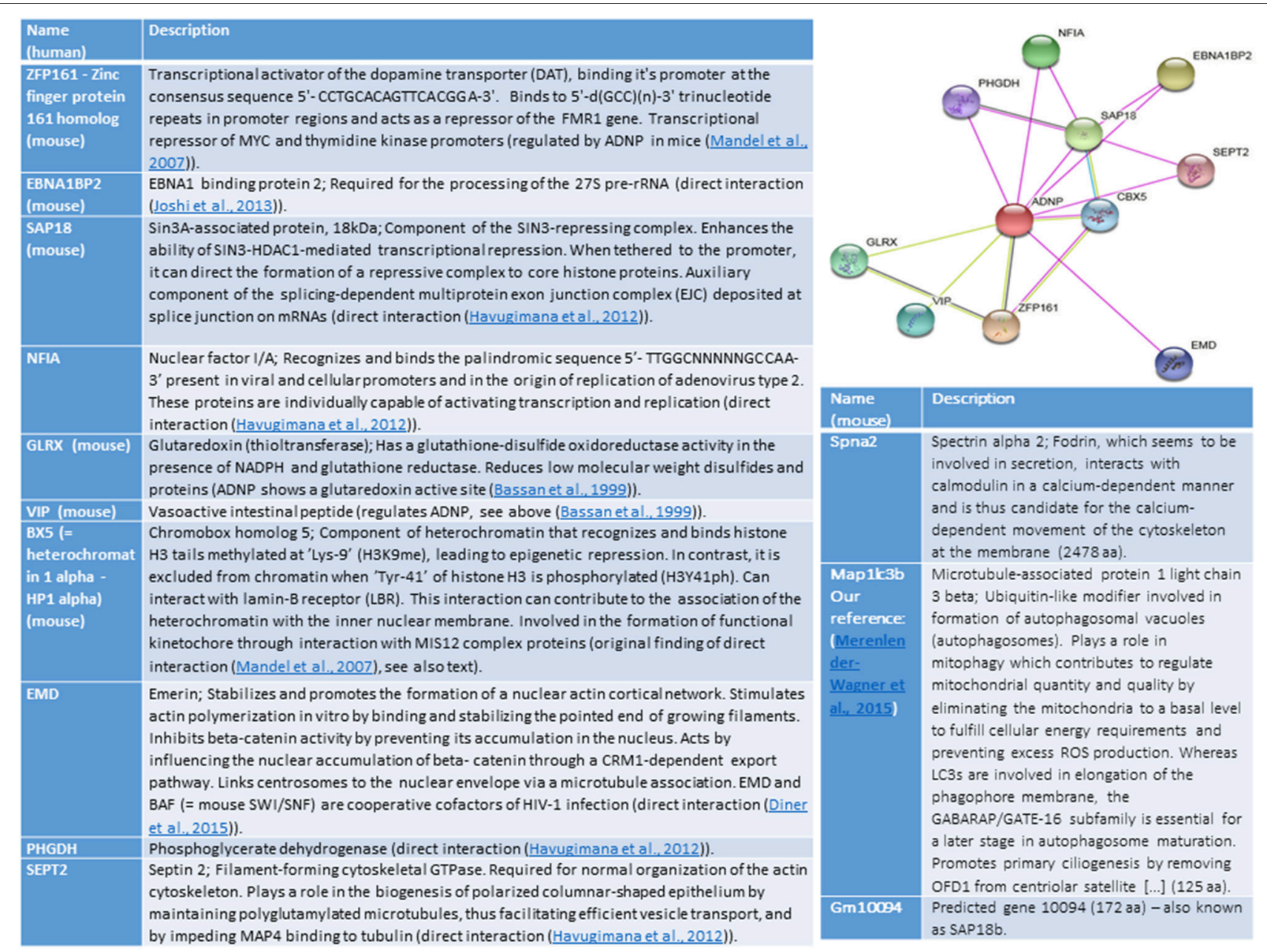

FIGURE 1 | The illustration shows ADNP interactions (String analysis, https://string-db.org/cgi/network.pl?taskld=P3YfAA8ZrZzy). Edges represent protein-protein associations, Known-interactions from curated databases are shown in light blue, experimentally determined are in magenta. Predicted Interactions include, gene neighborhood (green) gene fusions (red) gene co-occurrence (violet), textmining (light green), co-expression (black) and protein homology (light violet). References cited in the figure and not cited above include (Havugimana et al., 2012; Joshi et al., 2013; Diner et al., 2015).

Furthermore, NAP activity is not limited to the mouse model, but has shown efficacy in amnestic mild cognitive impairment patients, prodromal to Alzheimer's disease (protecting short term memory) and in schizophrenia patients (protecting functional activities of daily living as reviewed; Magen and Gozes, 2013, 2014). Currently, Coronis Neurosciences (www.coronisns.com) is developing NAP (CP201) for the ADNP syndrome.

\section{CONCLUSIONS}

This opinion article connects ADNP to a network of proteins linked with cognitive abilities. As many cases within the autism spectrum disorders and developmental disorders are caused by single gene mutations, it is of great interest to understand the protein interactions to get a comprehensive understanding of the molecular basis of cognition. Specifically, in the case of ADNP, which has been correlated with intelligence in the developing child and in the elderly, in autism spectrum disorders, the ADNP syndrome, in Alzheimer's disease and cognitive impairments associated with schizophrenia. The case of ADNP is unique with the identification of its active neuroprotective site, NAP. Outlined above are protein interacting with the multitasking ADNP, which are linked in part to neurodevelopment and cognition. For example, mutations in CHD4 (OMIM \# 617159) cause neurodevelopmental delays, chromatin remodelers have been associated with cognition (Wenderski and Maze, 2016), Eif4e has been tightly linked with autism (St Clair and Johnstone, 2018) and autophagy with autism, brain degeneration and schizophrenia (Sragovich et al., 2017). Finally, ADNP's interaction with cytoskeletal proteins shapes the synapse and contributes to brain plasticity (Gozes et al., 2018; HacohenKleiman et al., 2018). Understanding ADNP multitasks and interacting proteins, will allow the development of NAP and pipeline for other related diseases, syndromes affected by single 
gene mutations and allow cross-over drug repositioning clinical developments for the benefit of the cognitively impaired patient, families and society at large.

\section{AUTHOR CONTRIBUTIONS}

The author confirms being the sole contributor of this work and has approved it for publication.

\section{REFERENCES}

Ago, Y., Hayata, A., and Hashimoto, H. (2018). [Pathophysiological implication of the VPAC2 receptor in psychiatric disorders]. Nihon Yakurigaku Zasshi. 151, 249-253. doi: 10.1254/fpj.151.249

Amram, N., Hacohen-Kleiman, G., Sragovich, S., Malishkevich, A., Katz, J., Touloumi, O., et al. (2016). Sexual divergence in microtubule function: the novel intranasal microtubule targeting SKIP normalizes axonal transport and enhances memory. Mol. Psychiatry 21, 1467-1476. doi: 10.1038/mp. 2015.208

Arnett, A. B., Rhoads, C. L., Hoekzema, K., Turner, T. N., Gerdts, J., Wallace, A. S., et al. (2018). The autism spectrum phenotype in ADNP syndrome. Autism Res. 11, 1300-1310. doi: 10.1002/aur.1980

Bassan, M., Zamostiano, R., Davidson, A., Pinhasov, A., Giladi, E., Perl, O., et al. (1999). Complete sequence of a novel protein containing a femtomolaractivity-dependent neuroprotective peptide. J. Neurochem. 72, 1283-1293.

Blondel, O., Collin, C., McCarran, W. J., Zhu, S., Zamostiano, R., Gozes, I., et al. (2000). A glia-derived signal regulating neuronal differentiation. J. Neurosci. 20, 8012-8020. doi: 10.1523/JNEUROSCI.20-21-08012.2000

Bodner, M., Fridkin, M., and Gozes, I. (1985). Coding sequences for vasoactive intestinal peptide and PHM-27 peptide are located on two adjacent exons in the human genome. Proc. Nat. Acad. Sci. U.S.A. 82, 3548-3551.

Borozdin, W., Graham, J. M. Jr., Bohm, D., Bamshad, M. J., Spranger, S., Burke, L., et al. (2007). Multigene deletions on chromosome 20q13.13-q13.2 including SALL4 result in an expanded phenotype of Okihiro syndrome plus developmental delay. Hum. Mutat. 28:830. doi: 10.1002/humu.9502

Brenneman, D. E., and Eiden, L. E. (1986). Vasoactive intestinal peptide and electrical activity influence neuronal survival. Proc. Natl Acad. Sci. U.S. A. 83, 1159-1162. doi: 10.1073/pnas.83.4.1159

Deciphering Developmental Disorders (2017). Prevalence and architecture of de novo mutations in developmental disorders. Nature 542, 433-438. doi: $10.1038 /$ nature 21062

Diner, B. A., Li, T., Greco, T. M., Crow, M. S., Fuesler, J. A., Wang, J., et al. (2015). The functional interactome of PYHIN immune regulators reveals IFIX is a sensor of viral DNA. Mol. Syst. Biol. 11:787. doi: 10.15252/msb.20145808

Dresner, E., Malishkevich, A., Arviv, C., Leibman Barak, S., Alon, S., Ofir, R., et al. (2012). Novel evolutionary-conserved role for the activity-dependent neuroprotective protein (ADNP) family that is important for erythropoiesis. J. Biol. Chem. 287, 40173-40185. doi: 10.1074/jbc.M112.387027

Esteves, A. R., Gozes, I., and Cardoso, S. M. (2014). The rescue of microtubuledependent traffic recovers mitochondrial function in Parkinson's disease. Biochim. Biophys. Acta 1842, 7-21. doi: 10.1016/j.bbadis.2013.10.003

Giladi, E., Hill, J. M., Dresner, E., Stack, C. M., and Gozes, I. (2007). Vasoactive intestinal peptide (VIP) regulates activity-dependent neuroprotective protein (ADNP) expression in vivo. J. Mol. Neurosci. 33, 278-283. doi: 10.1007/s12031-007-9003-0

Gozes, I., Bardea, A., Reshef, A., Zamostiano, R., Zhukovsky, S., Rubinraut, S., et al. (1996). Neuroprotective strategy for Alzheimer disease: intranasal administration of a fatty neuropeptide. Proc. Natl Acad. Sci. U.S.A. 93, 427-432.

Gozes, I., Helsmoortel, C., Vandeweyer, G., N., Van der Aa, Kooy, F., and Sermone, S. B. (2015). The Compassionate side of neuroscience: tony sermone's undiagnosed genetic journey-ADNP mutation. J. Mol. Neurosci. 56, 751-757. doi: 10.1007/s12031-015-0586-6

Gozes, I., Ivashko-Pachima, Y., and Sayas, C. L. (2018). ADNP, a microtubule interacting protein, provides neuroprotection through end binding

\section{FUNDING}

Research was supported by funds from the Israel Science Foundation (ISF) grant (1424/14), ERA-NET neuron AUTYSM, AMN Foundation, Drs. Ronith and Armand Stemmer and Mr. Arthur Gerbi (French Friends of Tel Aviv University), as well as Canadian (Mrs. Anne and Mr. Alex Cohen) and Spanish Friends of Tel Aviv University.

proteins and tau: an amplifier effect. Front. Mol. Neurosci. 11:151. doi: $10.3389 /$ fnmol.2018.00151

Gozes, I., Patterson, M. C., Van Dijck, A., Kooy, R. F., Peeden, J. N., Eichenberger, J. A., et al. (2017a). The eight and a half year journey of undiagnosed ad: gene sequencing and funding of advanced genetic testing has led to hope and new beginnings. Front. Endocrinol. 8:107. doi: 10.3389/fendo.2017. 00107

Gozes, I., Perl, O., Giladi, E., Davidson, A., Ashur-Fabian, O., Rubinraut, S., et al. (1999). Mapping the active site in vasoactive intestinal peptide to a core of four amino acids: neuroprotective drug design. Proc. Natl Acad. Sci. U.S.A. 96, $4143-4148$

Gozes, I., Shani, Y., and Rostène, W. H. (1987). Developmental expression of the VIP-gene in brain and intestine. Brain Res. 388, 137-148. doi: 10.1016/0169-328X(87)90007-6

Gozes, I., Van Dijck, A., Hacohen-Kleiman, G., Grigg, I., Karmon, G., Giladi, E., et al. (2017b). Premature primary tooth eruption in cognitive/motor-delayed ADNP-mutated children. Transl. Psychiatry 7:e1043. doi: 10.1038/tp.2017.27

Hacohen-Kleiman, G., Sragovich, S., Karmon, G., Gao, A. Y. L., Grigg, I., Pasmanik-Chor, M., et al. (2018). Activity-dependent neuroprotective protein deficiency models synaptic and developmental phenotypes of autism-like syndrome. J. Clin. Invest. 128, 4956-4969. doi: 10.1172/JCI98199

Havugimana, P. C., Hart, G. T., Nepusz, T., Yang, H., Turinsky, A. L., Li, Z., et al. (2012). A census of human soluble protein complexes. Cell 150, 1068-1081. doi: 10.1016/j.cell.2012.08.011

Helsmoortel, C., Vulto-van Silfhout, A. T., Coe, B. P., Vandeweyer, G., Rooms, L., van den Ende, J., et al. (2014). A SWI/SNF-related autism syndrome caused by de novo mutations in ADNP. Nat. Genet. 46, 380-384. doi: 10.1038/ng.2899

Huynh, M. T., Boudry-Labis, E., Massard, A., Thuillier, C., Delobel, B., DubanBedu, B., et al. (2018). A heterozygous microdeletion of 20q13.13 encompassing ADNP gene in a child with Helsmoortel-van der Aa syndrome. Eur. J. Hum. Genet. 26, 1497-1501. doi: 10.1038/s41431-018-0165-8

Ivashko-Pachima, Y., Sayas, C. L., Malishkevich, A., and Gozes, I. (2017). ADNP/NAP dramatically increase microtubule end-binding protein-Tau interaction: a novel avenue for protection against tauopathy. Mol. Psychiatry 22, 1335-1344. doi: 10.1038/mp.2016.255

Joshi, P., Greco, T. M., Guise, A. J., Luo, Y., Yu, F., Nesvizhskii, A. I., et al. (2013). The functional interactome landscape of the human histone deacetylase family. Mol. Syst. Biol. 9:672. doi: 10.1038/msb.2013.26

Larsen, E., Menashe, I., Ziats, M. N., Pereanu, W., Packer, A., and BanerjeeBasu, S. (2016). A systematic variant annotation approach for ranking genes associated with autism spectrum disorders. Mol. Autism 7:44. doi: 10.1186/s13229-016-0103-y

Magen, I., and Gozes, I. (2013). Microtubule-stabilizing peptides and small molecules protecting axonal transport and brain function: focus on davunetide (NAP). Neuropeptides 47, 489-495. doi: 10.1016/j.npep.2013.10.011

Magen, I., and Gozes, I. (2014). Davunetide: peptide therapeutic in neurological disorders. Curr. Med. Chem. 21, 2591-2598. doi: 10.2174/0929867321666140217124945

Malishkevich, A., Amram, N., Hacohen-Kleiman, G., Magen, I., Giladi, E., and Gozes, I. (2015). Activity-dependent neuroprotective protein (ADNP) exhibits striking sexual dichotomy impacting on autistic and Alzheimer's pathologies. Transl. Psychiatry 5:e501. doi: 10.1038/tp.2014.138

Malishkevich, A., Marshall, G. A., Schultz, A. P., Sperling, R. A., Aharon-Peretz, J., and Gozes, I. (2016). Blood-borne activity-dependent neuroprotective protein (ADNP) is correlated with premorbid intelligence, clinical stage, 
and Alzheimer's disease biomarkers. J. Alzheimer's Dis. 50, 249-260. doi: 10.3233/JAD-150799

Mandel, S., and Gozes, I. (2007). Activity-dependent neuroprotective protein constitutes a novel element in the SWI/SNF chromatin remodeling complex. J. Biol. Chem. 282, 34448-34456. doi: 10.1074/jbc.M704756200

Mandel, S., Rechavi, G., and Gozes, I. (2007). Activity-dependent neuroprotective protein (ADNP) differentially interacts with chromatin to regulate genes essential for embryogenesis. Dev. Biol. 303, 814-824. doi: 10.1016/j.ydbio.2006.11.039

Mandel, S., Spivak-Pohis, I., and Gozes, I. (2008). ADNP differential nucleus/cytoplasm localization in neurons suggests multiple roles in neuronal differentiation and maintenance. J. Mol. Neurosci. 35, 127-141. doi: 10.1007/s12031-007-9013-y

Merenlender-Wagner, A., Malishkevich, A., Shemer, Z., Udawela, M., Gibbons, A., Scarr, E., et al. (2015). Autophagy has a key role in the pathophysiology of Schizophrenia. Mol. Psychiatry 20, 126-132. doi: 10.1038/mp.2013.174

Mosch, K., Franz, H., Soeroes, S., Singh, P. B., and Fischle, W. (2011). HP1 recruits activity-dependent neuroprotective protein to $\mathrm{H} 3 \mathrm{~K} 9 \mathrm{me} 3$ marked pericentromeric heterochromatin for silencing of major satellite repeats. PLoS ONE 6:e15894. doi: 10.1371/journal.pone.0015894

Ostapcuk, V., Mohn, F., Carl, S. H., Basters, A., Hess, D., Iesmantavicius, V., et al. (2018). Activity-dependent neuroprotective protein recruits HP1 and CHD4 to control lineage-specifying genes. Nature 557, 739-743. doi: 10.1038/s41586-018-0153-8

Pinhasov, A., Mandel, S., Torchinsky, A., Giladi, E., Pittel, Z., Goldsweig, A. M., et al. (2003). Activity-dependent neuroprotective protein: a novel gene essential for brain formation. Brain Res. Dev. Brain Res. 144, 83-90. doi: 10.1016/S0165-3806(03)00162-7

Schirer, Y., Malishkevich, A., Ophir, Y., Lewis, J., Giladi, E., and Gozes, I. (2014). Novel marker for the onset of frontotemporal dementia: early increase in activity-dependent neuroprotective protein (ADNP) in the face of Tau mutation. PLoS ONE 9:e87383. doi: 10.1371/journal.pone.0087383

Sragovich, S., Merenlender-Wagner, A., and Gozes, I. (2017). ADNP plays a key role in autophagy: from autism to schizophrenia and alzheimer's disease. BioEssays 39:1700054. doi: 10.1002/bies.201700054

St Clair, D., and Johnstone, M. (2018). Using mouse transgenic and human stem cell technologies to model genetic mutations associated with schizophrenia and autism. Philos. Trans. R. Soc. Lond. B Biol. Sci. 373:20170037. doi: 10.1098/rstb.2017.0037

Stessman, H. A., Xiong, B., Coe, B. P., Wang, T., Hoekzema, K., Fenckova, M., et al. (2017). Targeted sequencing identifies 91 neurodevelopmental-disorder risk genes with autism and developmental-disability biases. Nat. Genet. 49, 515-526. doi: 10.1038/ng.3792

Vacic, V., McCarthy, S., Malhotra, D., Murray, F., Chou, H. H., Peoples, A., et al. (2011). Duplications of the neuropeptide receptor gene VIPR2 confer significant risk for schizophrenia. Nature 471, 499-503. doi: 10.1038 /nature09884

Van Dijck, A., Vulto-van Silfhout, A. T., Cappuyns, E., van der Werf, I. M., Mancini, G. M., Tzschach, A., et al. (2018). Clinical Presentation of a complex neurodevelopmental disorder caused by mutations in ADNP. Biol. Psychiatry. doi: 10.1016/j.biopsych.2018.02.1173. [Epub ahead of print].

Vandeweyer, G., Helsmoortel, C., Van Dijck, A., A. T., Vulto-van Silfhout, Coe, B. P., Bernier, R., et al. (2014). The transcriptional regulator ADNP links the BAF (SWI/SNF) complexes with autism. Am. J. Med. Genet. Part C Semin. Med. Genet. 166C, 315-326. doi: 10.1002/ajmg.c. 31413

Vulih-Shultzman, I., Pinhasov, A., Mandel, S., Grigoriadis, N., Touloumi, O., Pittel, Z., et al. (2007). Activity-dependent neuroprotective protein snippet NAP reduces tau hyperphosphorylation and enhances learning in a novel transgenic mouse model. J. Pharmacol. Exp. Therap. 323, 438-449. doi: 10.1124/jpet.107.129551

Wenderski, W., and Maze, I. (2016). Histone turnover and chromatin accessibility: critical mediators of neurological development, plasticity, and disease. BioEssays 38, 410-419. doi: 10.1002/bies.201500171

Zamostiano, R., Pinhasov, A., Gelber, E., Steingart, R. A., Seroussi, E., Giladi, E., et al. (2001). Cloning and characterization of the human activity-dependent neuroprotective protein. J. Biol. Chem. 276, 708-714. doi: $10.1074 /$ jbc.M007416200

Zusev, M., and Gozes, I. (2004). Differential regulation of activity-dependent neuroprotective protein in rat astrocytes by VIP and PACAP. Regul. Peptides 123, 33-41. doi: 10.1016/j.regpep.2004.05.021

Conflict of Interest Statement: IG is the Chief Scientific Officer of Coronis Neurosciences, developing CP201 (under patent protection and license from Ramot at Tel Aviv University).

Copyright (c) 2018 Gozes. This is an open-access article distributed under the terms of the Creative Commons Attribution License (CC BY). The use, distribution or reproduction in other forums is permitted, provided the original author(s) and the copyright owner(s) are credited and that the original publication in this journal is cited, in accordance with accepted academic practice. No use, distribution or reproduction is permitted which does not comply with these terms. 